\title{
DAMAGE-FREE PHOTO-ASSISTED CRYOGENIC ETCHING OF GaN AS EVIDENCED BY REDUCTION OF YELLOW LUMINESCENCE
}

\author{
J. T. Hsieh, J. M. Hwang and H. L. Hwang \\ Institute of Electronic Engineering, National Tsing-Hua University, \\ Hsinchu, 300, Taiwan, R.O.C. \\ W. H. Hung \\ Synchrotron Radiation Research Center, Hsinchu, 300, Taiwan, R.O.C.
}

\begin{abstract}
Damage-free etching of $\mathrm{GaN}$ by $\mathrm{Cl}_{2}$, assisted by an $\operatorname{ArF}(193 \mathrm{~nm}$ ) excimer laser, is demonstrated. At low temperatures, photo-assisted etching can provide a better etch rate and largely improve the surface morphology and quality. AFM results show that the etched GaN surface is obtained with a root-mean-square roughness of $1.7 \mathrm{~nm}$. As compared with the photoluminescence spectra of photoelectrochemical wet etched $\mathrm{GaN}$, the photo-assisted cryogenic etching is proved to be a damage-free dry etching technique.
\end{abstract}

\section{INTRODUCTION}

GaN and related substrates have good thermal stability and excellent chemical inertness because of their strong bond strengths. This has made it difficult to develop controlled etch processes to successfully realize III-nitride based devices. Most of the previous work has been directed toward mesa formation in UV/blue/green laser diodes, where etch depths are relatively large $(2-4 \bullet \mathrm{m})$ and the final surface morphology is relatively unimportant. Most attention is paid to a smooth vertical facet. On the other hand, the etching requirements for high power/high temperature electronics are quite different. With shallower etch depths, the fabrication of these devices is on retaining smooth surface morphologies and obtaining high etch selectivity for one material to another. In the past, chemically assisted ion beam etching (CAIBE) ${ }^{1}$, reactive ion etching (RIE) ${ }^{2}$ and inductively coupled plasma (ICP) ${ }^{3}$ etching techniques have been used to etch $\mathrm{GaN}$ and related compounds. Despite high etch rates and good anisotropy etching have been obtained from these techniques, it is difficult to produce a perfect facet and damage-free sidewall and bottom surface due to the bombardment of energetic ions.

Based on the above discussions, photo-assisted etching appears to be an alternative method to resolve these problems. Photo-induced etching is initiated as a result of direct absorption of photons by adsorbate molecules on the semiconductor substrate. Subsequently, the photostimulated chemical reaction occurs to form volatile products, which may desorb from the surface and are exhausted out by the pumping system to complete the etching process. Desorption of product species plays a key role in determining the etching characteristics. By cryogenic cooling of the substrate during photo-assisted etching, thermal reaction and desorption are suppressed. It provides a route for an anisotropic etching process with the damage-free surface. The advantage of etching at low temperatures also includes the fact that the sticking coefficient of $\mathrm{Cl}_{2}$ on the substrate is increased.

In previous work, Shih et al. ${ }^{4}$ presented a technique for cryogenic chlorine etching of GaAs. Leonard and Bedair ${ }^{5}$ also obtained successful realization of photoassisted etching of $\mathrm{GaN}$ in $\mathrm{HCl}$ 
by using a $193 \mathrm{~nm}$ ArF excimer laser. In Leonard's experiment, $\mathrm{HCl}$ etchant with a base pressure of $\sim 5 \times 10^{-4}$ Torr, a sample temperature between 200 and $400{ }^{\circ} \mathrm{C}$ and a laser fluence of 1400 $\mathrm{mJ} / \mathrm{cm}^{2}$ were combined to produce an etch rate of $8 \mathrm{~nm} / \mathrm{min}$. In this letter we will show the preliminary results and demonstrate the improved $\mathrm{GaN}$ surface quality using photo-assisted cryogenic etching laser in $\mathrm{Cl}_{2}$ ambient with an $\mathrm{ArF}$ excimer. Photoelectrochemical (PEC) etching experiments is also performed to compare with the results of photo-assisted cryogenic (PAC) etching.

Table I. A L $\mathrm{L}_{16} 4^{4}$ Taguchi orthogonal design of various parameters in PAC etching.

\begin{tabular}{|c|c|c|c|c|}
\hline Parameter & $\begin{array}{c}\text { Laser Power } \\
(\mathrm{mJ})\end{array}$ & $\begin{array}{c}\mathrm{Cl}_{2} \text { pressure } \\
(\mathrm{mTorr})\end{array}$ & $\begin{array}{c}\text { Repetition Rate } \\
(\mathrm{Hz})\end{array}$ & $\begin{array}{c}\text { Temperature } \\
\left({ }^{\circ} \mathrm{C}\right)\end{array}$ \\
\hline 1 & 270 & 0.1 & 1 & +100 \\
\hline 2 & 300 & 0.5 & 2 & +25 \\
\hline 3 & 210 & 1 & 4 & -60 \\
\hline 4 & 240 & 5 & 8 & -170 \\
\hline
\end{tabular}

\section{EXPERIMENT}

A high vacuum etching system was composed of a load lock, a preparation chamber and the main etching chamber. The main chamber was turbo pumped maintaining a base pressure of $8 \mathrm{x}$ $10^{-9}$ Torr when the system was not in use. $\mathrm{Cl}_{2}$ was introduced into the chamber via a leak valve doser. Liquid nitrogen was used to cool down the sample holder to $100 \mathrm{~K}$. For the purpose of studying the relationship between various parameters and etch rate, a sixteen-run experiment using $\mathrm{L}_{16} 4^{4}$ Taguchi orthogonal design was employed. The experimental parameters in this study are listed in Table I.

The light source was a Lambda Physik LPX-200 ArF excimer laser (193 nm). The n-type $\mathrm{GaN}\left(\leq 5 \times 10^{16} \mathrm{~cm}^{-3}\right)$ samples, epitaxially grown on the sapphire substrate, were purchased from CREE Corporation. Prior to the sample mounting, the samples were solvent cleaned. A stainless plate with small holes was used to serve as the overlaid mask. Before introducing the laser beam through a quartz window into the etching chamber, one reflection mirror and one focus lens of $15-\mathrm{cm}$ focus length were arranged to direct the beam path. The beam output power measured in front of the quartz window was $210-300 \mathrm{~mJ} / \mathrm{pulse}$. The focus lens reduced the laser beam spot size on the substrate to $10 \%$ of its original $3 \times 1 \mathrm{~cm}^{2}$ dimensions.

For the damage identification study, PEC etched samples were prepared to compare with that obtained from PAC etching. The illumination source for PEC etching was an ORIEL $1000 \mathrm{~W}$ $\mathrm{Hg}$ lamp, which was generally operated at $600 \mathrm{~W}$. To avoid the heating problem from the electrolyte absorption, a water reservoir was mounted in front of the exit window of the $\mathrm{Hg}$ lamp to filter out the infared radiation. The samples were clipped between a Pt electrode plate with a 4 mm hole and a Teflon holder. A Teflon mask with a $3 \mathrm{~mm}$ hole was used to cover and prevent the Pt electrode from UV illumination. The electrolyte was prepared by dissolving potassium hydroxide $(\mathrm{KOH})$ pellets in deionized water to form a $0.02 \mathrm{M}$ aqueous solution. The standard liftoff lithography technique was used to form the $100 \bullet \mathrm{m}$ square Ti metal mask that served as an ohmic contact for better photocurrent conduction.

A continuous wave He-Cd laser with $\bullet_{\text {exc }}=325.0 \mathrm{~nm}$ was used in the photoluminescence (PL) mesurement. All PL spectra were recorded using a monochrometer and a photomultiplier. 


\section{RESULTS AND DISCUSSION}
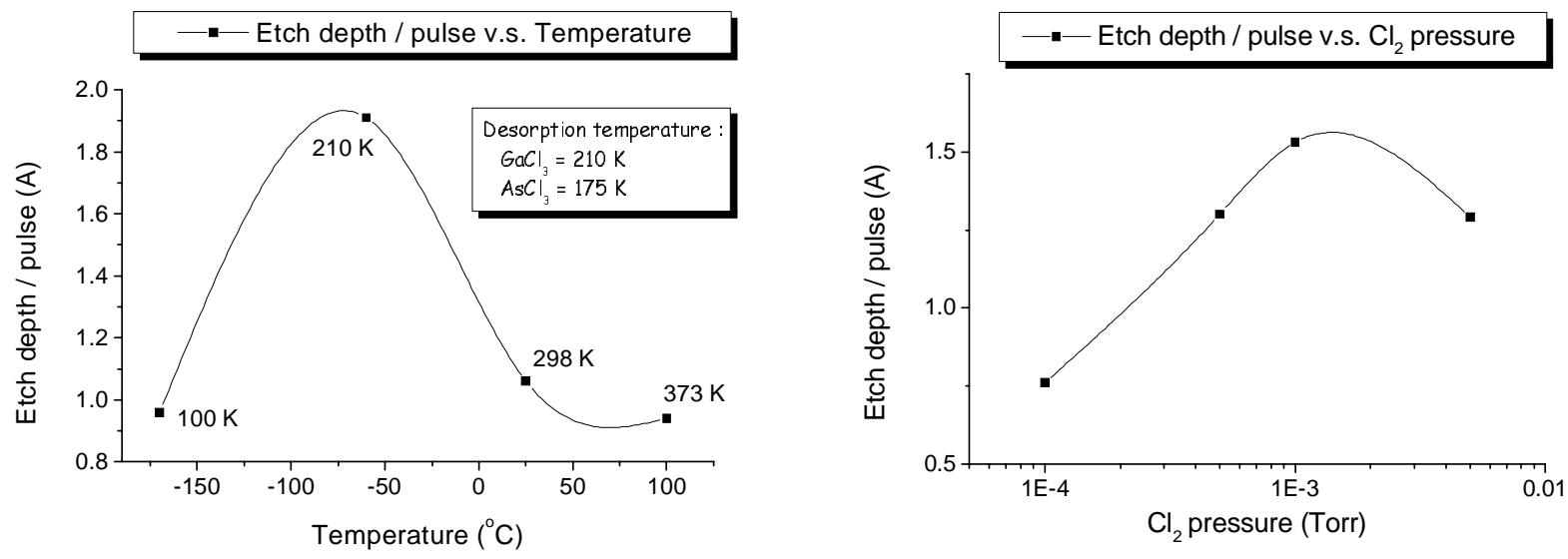

Figure 1. Etch depth/pulse as a function of (a) temperature and (b) $\mathrm{Cl}_{2}$ pressure.


Figure 2. SEM and AFM photographs of photo-assisted cryogenic etched GaN surfaces.

Figure 1(a) shows the GaN etch rates as a function of temperature. The etch depth is measured using an alpha-step and a maximum etch rate of $84 \mathrm{~nm} / \mathrm{mim}$ is obtained at $210 \mathrm{~K}$. As compared with Leonard and Bedair's results ${ }^{5}$, the increased etch rate may be attributed to the higher efficiency of $\mathrm{Cl}$ radical production since the $\mathrm{Cl}-\mathrm{Cl}$ binding energy $(242.58 \mathrm{~kJ} / \mathrm{mol}$ at $298 \mathrm{~K})$ is smaller than that of the $\mathrm{H}-\mathrm{Cl}(431.62 \mathrm{~kJ} / \mathrm{mol}$ at $298 \mathrm{~K}){ }^{6}{ }^{6}$ In order to prevent the volatile product from residing on the surface during the course of etching, the surface must be kept above the desorption temperature to assure the etching to proceed. The etch rate also increases with the increase of laser power density. The linear dependence of the etch rate on the $\mathrm{Cl}_{2}$ pressure is shown in Fig. 1(b). The etch rate increases with the decrease of temperature and the increase of $\mathrm{Cl}_{2}$ pressure. This suggests that the etching process is initiated by $\mathrm{Cl}$ atoms photogenerated from the physisorbed chlorine layer on the substrate. At lower temperature, more molecular chlorine is condensed on the surface, which is photodissociated and reacts with the GaN substrate. However, the etch rate becomes saturated at a $\mathrm{Cl}_{2}$ pressure of $\sim 1 \mathrm{mTorr}$ and then decreases at higher pressures. The threshold of laser power density is estimated to be about $600 \mathrm{~mJ} / \mathrm{cm}^{2}$. No appreciable etching is observed when the substrate is exposed to $\mathrm{Cl}_{2}$ without laser illumination or a laser illumination without $\mathrm{Cl}_{2}$ introduction. The combination of both $\mathrm{Cl}_{2}$ and $\mathrm{ArF}$ laser energy is a necessary condition to proceed the photo-assisted etching. It is also found that the ablative etching occurs at the power density of more than $1000 \mathrm{~mJ} / \mathrm{cm}^{2}$. 
Table II. A comparison of the roughness of the etched GaN surface in the previous studies and this work.

\begin{tabular}{|c|c|c|c|}
\hline Gas & Roughness $(\mathrm{nm})$ & Etch technique & References \\
\hline $\mathrm{Cl}_{2} / \mathrm{H}_{2} / \mathrm{CH}_{4} / \mathrm{Ar}$ & 65.2 & ICP & 10 \\
\hline $\mathrm{Cl}_{2} / \mathrm{H}_{2} / \mathrm{CH}_{4} / \mathrm{Ar}$ & 19.3 & RIE/ECR & 10 \\
\hline $\mathrm{Cl}_{2} / \mathrm{Ar}$ & 5.4 & ICP & 3 \\
\hline $\mathrm{BI}_{3} / \mathrm{Ar}$ & $\sim 10$ & ICP & 11 \\
\hline $\mathrm{BBr}_{3} / \mathrm{Ar}$ & $\sim 3$ & ICP & 11 \\
\hline $\mathrm{Cl}_{2}$ & $\sim 1.7$ & PAC & This work \\
\hline
\end{tabular}

As shown in Figure 2, SEM and atomic force microscopy (AFM) photographs indicate that the root-mean-square roughness of $1.7 \mathrm{~nm}$ can be achieved on $\mathrm{GaN}$ surface etched at $210 \mathrm{~K}$. The surface roughness of $\mathrm{GaN}$ etched at low temperatures is much better than that obtained at room temperature. It can be inferred that the higher sticking coefficient of $\mathrm{Cl}_{2}$ at low temperatures helps to etch the substrate more efficiently. Compared with the results using RIE/ECR-RIE/ICP dry etching techniques, photo-assisted cryogenic etching produces the smoothest surface. Table II lists some roughness data reported in the previous studies using other etching techniques and conditions.

Figurs 3(a) shows the room temperature PL spectrum of PAC etched GaN surfaces. The $3.41 \mathrm{eV}$ peak is attributed to the near-band-edge emission and the $1.705 \mathrm{eV}$ peak is its second harmonic conterpart. A broad yellow luminescence (YL) is observed for the GaN surface etched at room temperature, which is centered at $2.2 \mathrm{eV}$. But it does not appear at the GaN surface etched at low tempertures. For further investigation on this broad band emission, PL spectra of PEC etched GaN surfaces are shown in Figure 3(b). All PEC etched surfaces show a broad band emission and its relative intensity increases with the increase of the UV radiation power. On the GaN surface etched under the irradiation of $700 \mathrm{~W} \mathrm{UV}$, the peak shifts from $3.41 \mathrm{eV}$ to the lower energy. The origin of yellow luminescence has attracted much attention and several mechanisms have been proposed. Neugebauer and Van De Walle ${ }^{7}$ investigated the native vacancy defect and vacancy-impurity complexes and suggested that the main defect source is attributed to $\mathrm{V}_{\mathrm{Ga}}(\mathrm{Ga}$ vacancy) forming an acceptor-like defect level. From the first-principle calculation, they concluded that $\mathrm{V}_{\mathrm{Ga}}$ is easier to form due to its lower formation energy and is possibly the origin of YL. During the photo-assisted etching of $\mathrm{GaN}, \mathrm{Ga}$ is removed as volatile $\mathrm{GaCl}_{\mathrm{x}}$ products via a photo-stimulated reaction while $\mathrm{N}$ is most likely removed as a free atom. This process creates a Ga-deficient surface and results in the acceptor-like native defect, namely, gallium vacancy that is the origin of YL as proposed by Neugebauer and Van De Walle. The use of cryogenic temperatures for the substrate increases the range of usable molecular adsorbates and suppresses unwanted thermally active reactions that normally occur at room temperature. Hence, the defect center is largely reduced and no YL band is observed on the photo-assisted cryoetched GaN surfaces. On the other hand, Minsky et al. ${ }^{8}$ proposed that the PEC etching of GaN occurs through the oxidative decomposition, in which photogenerated holes assist the oxidation and the subsequent dissolution of the semiconductor into aqueous solution. Youtsey et al. ${ }^{9}$ postulated that the oxidation reaction, $2 \mathrm{GaN}+6 h^{+} \rightarrow 2 \mathrm{Ga}^{3+}+\mathrm{N}_{2}$, is responsible for the decomposition of GaN. While in our wet etching condition, we tentatively conjecture that YL may result from deep level $\mathrm{V}_{\mathrm{Ga}}$ and $\mathrm{V}_{\mathrm{Ga}}-\mathrm{O}_{\mathrm{N}}$ defect-impurity complexes. During the PEC etching, the oxidation reaction takes away $\mathrm{Ga}$ and $\mathrm{N}$ atoms $\left(\mathrm{V}_{\mathrm{Ga}}\right.$ and $\left.\mathrm{V}_{\mathrm{N}}\right)$ and incorporates $\mathrm{O}$ atoms into $\mathrm{N}$ sites to form the $\mathrm{V}_{\mathrm{Ga}}-\mathrm{O}_{\mathrm{N}}$ 
complexes, in which UV irradiation provides the enough formation energy. However, further experimental studies are needed to confirm this conjecture.
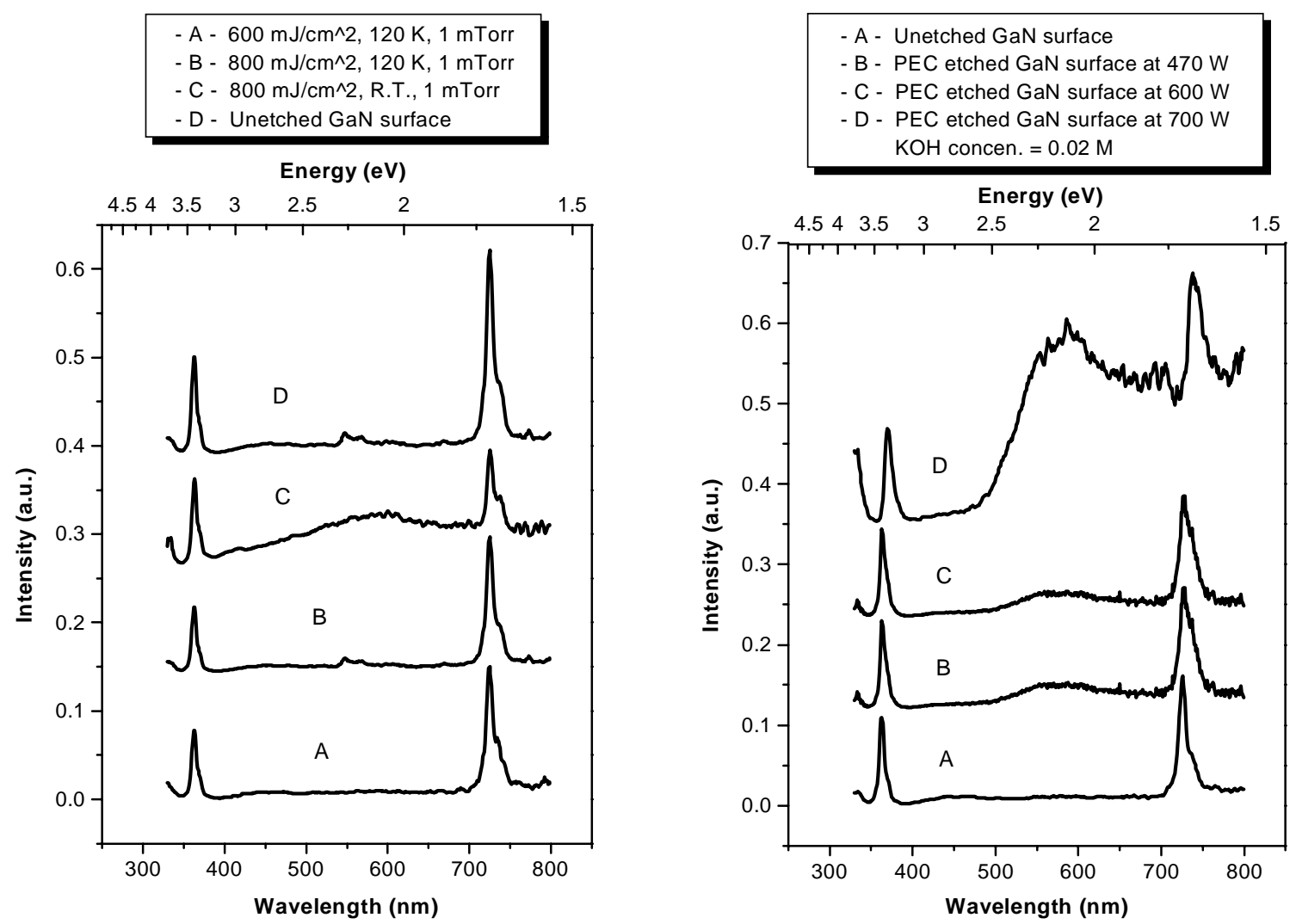

Fig. 3. PL spectra of (a) cryogenic photo-assisted and (b) photoelectrochemical etched GaN.
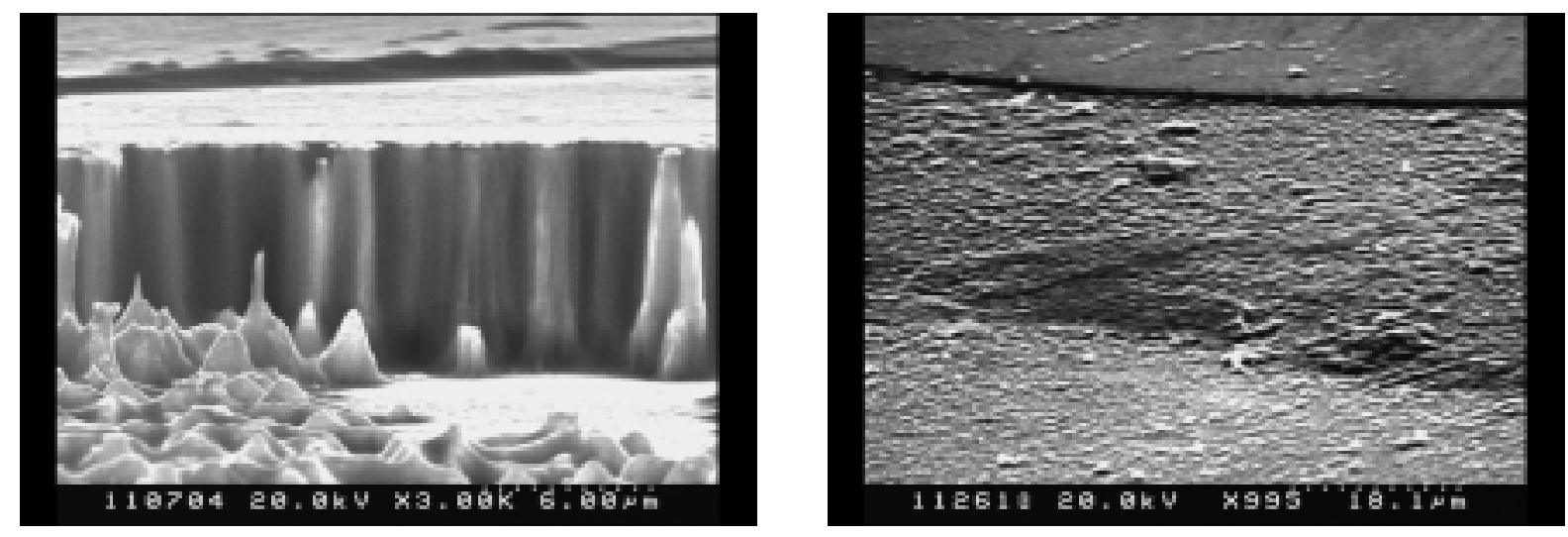

Fig. 4(a) SEM picture of photoelectrochemical etched $\operatorname{In}_{0.25} \mathrm{Ga}_{0.75} \mathrm{~N}$ at the elevated temperature in the $\mathrm{KOH}$ electrolyte with magnetic stirring. (b) SEM picture of photoelectrochemical etched GaN after a photo-assisted post-treatment. The post-treatment was conducted under $1 \mathrm{mTorr}^{\mathrm{Cl}_{2}}$ at R.T., with a laser power of $240 \mathrm{~mJ} /$ pulse and a repetition rate of $8 \mathrm{~Hz}$ for $10 \mathrm{mins}$.

We have also employed PAC and PEC techniques to etch InGaN samples. Like the GaN substrate, PAC etching of InGaN can produce a smooth vertical sidewall. But in the PEC etching, an indium oxide layer grows during etching and causes to slower the etching process. After 
stirring the electrolyte at the elevated temperature, we can continue the etching process and obtain a vertical sidewall as shown in Figure 4(a). It is also found that whiskers is formed on the GaN surface after PEC etching ${ }^{12}$. A post-treatment by $\mathrm{Cl}_{2}$ dry etching under the laser illuminaton, followed by PEC etching, can obtain a much improved smooth surface as shown in Figure 4(b).

\section{CONCLUSIONS}

In this study, PAC and PEC techniques are used to etch GaN and InGaN. The photoassisted cryogenic etching technigue can produce smooth and vertical sidewall features and resolve the yellow luminescence problem. Photoelectrochemical etching of $\mathrm{GaN}$ at room temperature is hindered by the formation of indium oxide. After stirring the $\mathrm{KOH}$ electrolyte at the elevated temperature, the vertical sidewall features can be achieved. The post-treatment of PEC etched $\mathrm{GaN}$ under a $\mathrm{Cl}_{2}$ ambient with the excimer laser illumination provides an alternative to obtain vertical and smooth etched surfaces.

\section{ACKNOWLEDGEMENT}

Financial support was provided by the Opto-Electronics and System Laboratories, Industrial Technology Research Insitute and National Science Council of Republic of China (Contract No. NSC 87-2215-E-007-031). The author would like to acknowledge the Material Science Research Center at National Tsing Hua University for the support of excimer laser.

\section{REFERENCES}

[1] A. T. Ping, A. C. Schmitz, M. Asif Khan and I. Adesida, J. Electronic Materials 25, 825 (1996).

[2] S. J. Pearton, C. B. Vartuli, R. J. Shul and J. C. Zolper, Mater. Sci. Eng. B31, 309 (1995).

[3] H. Cho, C. B. Vartuli, S. M. Donovan, J. D. Mackenzie, C. R. Abernathy, S. J. Pearton, R. J. Shul, and C. Constantine, J. Electronic Material 27, 166 (1998).

[4] M. C. Shih, M. B. Freiler, R. Scarmozzino and R. M. Osgood, Jr., J. Vac. Sci. Technol. B13, 43 (1995).

[5] R. T. Leonard and S. M. Bedair, Appl. Phys. Lett. 68, 794 (1996).

[6] D. R. Lide, CRC Handbook of Chemistry and Physics (Boca Raton: CRC press, 1992), p. 9129.

[7] J. Neugebauer and C. G. Van De Walle, Appl. Phys. Lett. 69, 503 (1996).

[8] M. S. Minsky, M. White, and E. L. Hu, Appl. Phys. Lett. 68, 1531 (1996).

[9] C. Youtsey, I. Adesida and G. Bulman, Appl. Phys. Lett. 71, 2151 (1997).

[10] R. J. Shul, G. B. McClellan, S. J. Pearton, C. R. Aberbathy, C. Constantine and C. Barratt, Electronics Letters, 32, 1408 (1996).

[11] H. Cho, J. Hong, T. Maeda, S. M. Donovan, C. R. Abernathy, S. J. Pearton, R. J. Shul, and J. Han, MRS Internet J. Nitride Semicond. Res. 3, 5 (1998).

[12] C. Youtsey, L. T. Romano and I. Adesida, Appl. Phys. Lett. 73, 797 (1998). 